\title{
Aerial Robotic Technologies for Civil Engineering: Established and Emerging Practice
}

M. R. Freeman, M.Eng.

Graduate Civil Engineer, Atkins Global. Formerly, MEng Student, University of Bristol, Department of Civil Engineering University of Bristol, Bristol, BS8 1TR, UK,

Email: mf15498@my.bristol.ac.uk ORCID: 0000-0002-6986-1429

M. M. Kashani, Ph.D.

Associate Professor, University of Southampton, Faculty of Engineering and Environment, Southampton, SO17 1BJ, UK, Email: mehdi.kashani@soton.ac.uk, ORCID: 0000-0003-0008-0007

\section{P. J. Vardanega, Ph.D.}

Senior Lecturer in Civil Engineering, University of Bristol, Department of Civil Engineering University of Bristol, Bristol, BS8 1TR, UK, Email: p.j.vardanega@bristol.ac.uk, OCRID: 00000001-7177-7851 (Corresponding Author).

\section{Word count:}

Approximately 8,600 (total words in document); 4 Tables (1000-word equivalents) 


\title{
Aerial Robotic Technologies for Civil Engineering: Established and Emerging Practice
}

\author{
M. R. Freeman, M. M. Kashani and P. J. Vardanega
}

ABSTRACT: Aerial robotic technology has potential for use in a wide variety of civil engineering applications. Such technology potentially offers low-cost methods to replace expensive structural health monitoring activities such as visual inspection. Aerial robots also have potential uses in civil construction and for regional surveys. This paper presents the results of a review on the applications of aerial robotic technology in civil engineering. Such civil engineering applications can be classified into three broad areas: (i) monitoring and inspection of civil infrastructure; (ii) site management, robotic construction, and maintenance and (iii) post-disaster response surveys and rapid damage assessments. The motivations for uptake of aerial robotics in the civil engineering industry generally fall into the following categories: (i) cost savings, (ii) improved measurement capability and (iii) safety improvements. The categories of aerial robotic use in civil engineering are then classified as either 'established' or 'emerging' uses.

KEYWORDS: Unmanned Aerial Vehicles (UAVs); Construction Site Management; PostDisaster Response Survey; Robotic Construction

\section{INTRODUCTION}

To better evaluate infrastructure performance, civil engineers require improved systems to monitor the infrastructure condition. This paper reviews the possible ways that aerial robotic technologies (often in the form of Unmanned Aerial Vehicles (UAVs)) can assist with collecting important data which can be used to better evaluate the performance of civil 
infrastructure (either single assets or a network of assets) during their construction and service

lives. UAVs are used in various military surveillance and reconnaissance applications (e.g., Kardasz et al., 2016). Recently, the technology has become available for business and recreational uses (Finn and Wright, 2012). UAVs are highly manoeuvrable, and their flexibility means they can provide visual access, in the form of photos or real-time videos, access difficult to reach areas quickly and at a relatively low cost. Many uses for UAVs are emerging in everyday life, for example the delivery of lightweight items to customers (e.g., Burgess, 2016; Hern, 2016; Shakhatreh et al. 2019). 3D models produced from aerial imagery can help to inspect infrastructure and assess situations (e.g., Lattanzi and Miller, 2015; Siebert and Teizer, 2014). The review of Shakhatreh et al. (2019) gives a detailed review of the market opportunities for UAV technology and they indicate that $45 \%$ of the total market for UAV technology relates to 'construction and infrastructure inspection' activities. The recent developments in sensor technology means that other types of data collection, i.e. thermal images, are possible despite UAVs limited payload (DeBell et al. 2015). UAVs are often regarded as a low-cost option as both the initial purchase costs and the operational costs compared to that of the equivalent labour hours are low (e.g., Park et al. 2012; Reagan et al. 2017) and decreasing (Greenwood et al. 2019).

In response to the dawn of the so called 'age of robots' (Hauert, 2016; Laschi et al. 2018), considerable research into the potential and emerging uses of robotics in many technical spaces including civil engineering has been reported. Therefore, it is timely to study how civil engineering may benefit from these technological advances. Many reviews including those of Liu et al. (2014), De Bell et al. (2015), Kardasz et al. (2016); Latanzi and Miller (2017), Recchiuto and Sgorbissa (2018), Albeanio et al. (2019), Greenwood et al. (2019) and Shakhatreh et al. (2019) give detailed reviews of the types of UAV platforms on the market: this aspect of the topic is beyond the scope of this review. The term 'Robophobia' (discussed 
in detail in Smith, 2018) is used in the context of people fearing robots replacing them in key functions (job losses). However, the societal and economic implications of increased uptake of robotic technologies in the civil engineering sector is beyond the scope of this review.

Some key review papers from the past decade are summarised in Table 1 . The review papers summarised in Table 1 have varying scopes in their coverage from the entire civil society domain in the case of Shakhatreh et al. (2019) to the narrower focus of Snook (2018) on safety and productivity in the context of infrastructure. This review is focussed on applications related to civil infrastructure and aims (in part) to classify different applications as 'emerging' or 'established'. Based on a literature review (see Freeman (2018) for a preliminary version) the use of aerial robotics in civil engineering can be broadly classified into three main areas (Table 2). Frederiksen et al. (2019) suggest motivations for the uptake of aerial robotic systems in infrastructure applications include: cost reduction; safety and environmental concerns (e.g., UAV's require less energy to operate than manned aircraft).

\section{MONITORING OF CIVIL INFRASTRUCTURE}

\section{Alternatives to visual inspection}

Monitoring existing infrastructure assets is vital to determining the safety of its continued use (cf. Reagan et al., 2017) and to allow for improved management of infrastructure networks especially during extreme events (e.g., Kaya et al. 2017). Infrastructure inspections must be carried out regularly and the most widely used method is for an inspector to visually assess the structure i.e. visual inspection (e.g., Ellenberg et al., 2015; Bennetts et al. 2016, 2020; Canning and Kashani, 2016; Omar and Nehdi, 2017). Visual inspection data can be unreliable as results are reliant on the inspector's own judgement and experience (e.g., McRobbie et al., 2015; Bennetts et al. 2018; Bolourian and Hammad et al. 2020; Popescu et al. 2019; Reagan et al., 2017; Vaghefi et al., 2012). Visual observation of cracks on the surface of structures is often considered a failure condition (or at least a warning of potential failure) (e.g., Kashani et al. 
2019), and are difficult to detect with the naked eye during inspections (e.g., McRobbie et al., 2015; Reagan et al., 2017). Usually, photographs are not taken of the entire structure during physical inspections, and hence monitoring changes of bridge condition is difficult (McRobbie et al., 2015, Bennetts et al., 2021). Additionally, human inspectors generally require machinery or scaffolding to inspect areas where access is limited (e.g., Popescu et al. 2019) and/or hazardous (e.g., high-voltage railway cables (e.g., Teng et al., 2017), which imposes a health and safety risk, auxiliary costs and commonly disrupts traffic (e.g., Omar and Nehdi, 2017; Reagan et al., 2017; Snook, 2018). By implementing aerial robotic technologies for structural inspections, many of the issues highlighted can be resolved. As a result, major infrastructure can be inspected more frequently. However, the challenge to locate 'hidden defects' (e.g., Collins et al. 2019) will remain and robotic technology will need to access all the parts of a structure that human inspectors currently are able to.

\section{Inspections using Photographs and Videos}

Aerial robotic technology may enable civil engineers to better retain and compare photographic records of the surface of structures or landforms (Hellmuth et al. 2018; Stewart et al. 2018) over time, making monitoring changes and specific defects easier (McRobbie et al., 2015). McRobbie et al. (2015) noted that this approach may be more reliable as inspections can be done in comfortable conditions and obtaining a second opinion is more feasible. Lattanzi and Miller (2014) and Lattanzi et al. (2016) developed a computer vision approach for detecting cracks in concrete structural elements from photography which was calibrated using laboratory experiments. For a detailed review on the use of computer vision in civil infrastructure assessment see Spencer et al. (2019). Robotic technologies are emerging as an alternative to visual inspections (Ham et al. (2016), Lattanzi and Miller (2017)). Ellenberg et al. (2015) investigated infrastructure inspection and found that far more quantitative measurements could be obtained using UAVs, i.e. 'damage detection’ (Webb et al. 2015). Kang and Cha (2018a, 
2018b) presented an autonomous UAV Structural Health Monitoring (SHM) system, tested in laboratory conditions, coupled with deep learning techniques for crack detection in concrete. UAVs have also been used to determine the conditions of geotechnical structures, slope stability assessments, monitoring bank erosion and lateral scour conditions (Hellmuth et al. 2018; Stewart et al, 2018; Thoeni et al. 2018).

Use of UAVs may eradicate the need to interrupt traffic flow when examining highway bridge structures, as there is no need for scaffolding or lane closures during the inspection (e.g., Omar and Nehdi, 2017; Reagan et al., 2017). However, Vaghefi et al. (2012) indicated that even though UAV data collection does not interfere with traffic, the preparation for inspection can require contact with the structure (i.e. the bridge), and hence traffic is often interrupted anyway. Furthermore, there might be some restrictions on UAV use in urban areas (e.g., Frederiksen et al. 2019).

\section{Inspections using 3D Reconstructions and Scanning}

Many authors have explored the idea of completing structural inspections from 3D reconstructions (although only some have undertaken practical experiments) (Ellenberg et al. 2015; Guerrero and Bestaoui, 2013; Park et al. 2012; Lattanzi and Miller, 2015; Omar and Nehdi, 2017; Reagan et al., 2017). Lattanzi and Miller (2015) compared the creation of a 3D model for structural inspections through 'Image Mosaicking (IM)' and 'Dense Structure from Motion (DSfM)' techniques. Lattanzi and Miller (2015) found that both IM and DSfM could generate models sufficient for structural inspections. Therefore, they recommended IM for simple and DSfM for more complex structures (Lattanzi and Miller, 2015). Digital Image Correlation (DIC) has also been used to inspect concrete bridges using images obtained from UAVs (Reagan et al. 2017). DIC allows inspectors to measure displacements and geometry profiles to the same accuracy as a dial calliper used in traditional inspections (Reagan et al. 2017). Ghahremani et al. (2018) present a laboratory tested methodology which can allow finite 
element (FE) models to be updated with sensed 3D point cloud data: with good agreement shown between the DIC results and the updated FE analysis. Bolourian and Hammad (2020) have reported use of UAV mounted light detection and ranging (LiDAR) scanning equipment to inspect bridge defects. The proposed 'path-planning' method used can be adapted for other sensing technologies (Bolourian and Hammad 2020). 3D reconstruction and scanning techniques can help with the building of 'Digital Twins’ of structures (e.g., Chacon et al. 2018; Kaewunruen and $\mathrm{Xu}, 2018)$. The measured data can be fused into the digital twin and be updated frequently (cf., Ghahremani et al. 2018). Use of digital twins has the potential to make evaluation of structural condition quicker, more accurate, safer, and more reliable.

\section{Inspections using Thermal Imaging}

Thermal imaging is increasingly used in civil engineering applications (e.g., Thusyanthan et al. 2017). Developments in thermal camera technology mean that they are now sufficiently lightweight to be mounted on UAVs (DeBell et al., 2015). Thermal imaging can be employed to detect subsurface issues in concrete bridge decks (e.g., Clark et al., 2003; Omar and Nehdi, 2017; Vaghefi et al., 2012). Material defects can cause deterioration, accelerated by the ageing of the structure and the environmental conditions (cf. Omar and Nehdi, 2017). Using thermal imaging techniques, subsurface delamination can be easily detected as the delamination interrupts the flow of heat through the concrete and creates an anomaly in the thermal image (e.g., Clark et al., 2003; Omar and Nehdi, 2017; Vaghefi et al., 2012). The reliability of the method may be compromised as material emissivity is influenced by surface roughness and moisture content, making constant emissivity across a surface unlikely (cf. Clark et al., 2003; Omar and Nehdi, 2017; Vaghefi et al., 2012).

Popescu et al. (2019) studied six bridges in Sweden comparing 3D models created with data from terrestrial laser scanning (TLS) (i.e. LiDAR), close range photogrammetry (CRP) (outlining the details of the camera and settings e.g., shutter speeds used) and infrared sensing 
152 (IS). The comparison between TLS, CRP and IS showed that as built bridge dimensions were measured to a reasonable accuracy, but the authors note that detecting deep defects with the aforementioned methods remains difficult.

\section{Motivations for increased use of aerial robotic technology}

The motivations for increased use of aerial robotic technology include: (i) cost savings, (ii) improved measurement capability and (iii) safety improvements. There are potential cost savings as less fixed infrastructure (e.g., wires and cables) are needed for monitoring deployments. Measurement flexibility may improve as human inspections can occur remotely and not in-situ which also leads to improved (safer) working environments for operators. However, the operators of robotic technology will still need to judge where damage is likely to occur on a structure. Therefore, such solutions may still suffer from the same problems of traditional visual inspection i.e. rate and extent of any located damage will still need to be interpreted by a human inspector (albeit remotely). Robotic data capture solutions may improve how data is captured but their use does not necessarily change or improve the engineering decisions that result from the collected data.

\section{SITE MANAGEMENT, ROBOTIC CONSTRUCTION AND MAINTENANCE}

Aerial robots can be used to monitor people entering and exiting secure facilities more effectively than static cameras, which can be costly and must be manually installed (Wen and Kang, 2014). Using aerial robotic technology to assist safety managers in monitoring health and safety conditions on site has been reported (e.g., Gheisari and Esmaeili, 2016; Irizarry and Costa, 2016) as well as to help visualise construction progress (e.g., Siebert and Teizer, 2014).

\section{Health and Safety Management}

Workplace health and safety managers need to manage risks onsite, which is currently done via visual inspection on site (Irizarry et al. 2012). Such inspections are subject to the experience 
and opinion of the manager, making it potentially an unreliable process (e.g., Irizarry et al. 2012) (as for visual inspection of bridge structures (e.g., Bennetts et al. 2018)). UAVs can provide a live video-feed of a jobsite, allowing inspections to be undertaken quickly and efficiently whilst also enabling a record to be kept (Irizarry et al. 2012). Video feeds can also be broadcast to multiple devices for authorised personnel to view (e.g., Wen and Kang, 2014). Gheisari and Esmaeilli (2016) surveyed safety managers to determine where they thought UAVs would be best employed. The study highlighted that UAVs were considered most helpful for monitoring employees working near boomed vehicles or cranes, close to edges or openings without protective barriers and to assist those operating in equipment blind spots (Gheisari and Esmaeilli 2016).

\section{Planning and Progress Assessments}

Site progress reports are generally collected manually either weekly or daily may lack objectivity or contain errors (Hui et al. 2015). Surveyors may sometimes have to work in dangerous environments, for example, a mine site (Siebert and Teizer, 2014). UAVs can provide images of the entire site and enables accurate measurements to be taken rather than assumptions made from brief inspections (e.g., Siebert and Teizer, 2014; Kaamin et al. 2017).

Producing 3D models is also a commonly discussed method of increasing the reliability and accuracy of progress assessments (e.g., Kaamin et al. 2017; Siebert and Teizer, 2014). Comparing 'as-planned’ Building Information Models (BIM) with 'as-built' models can help Project Managers determine if specific milestones have or have not been reached, and to what magnitude of difference, at each location (Alizadehsalehi et al. 2020; Siebert and Teizer, 2014); to show progression and when materials or additional resources will be required (potentially improving cost-efficiency) (Han et al. 2018; Siebert and Teizer, 2014). Siebert and Teizer (2014) compared UAV and Robotic Total Station (RTS) data for three earth piles using elevation maps generated using points taken from both devices (UAV giving a much larger 
number of measurement points than RTS). The surveyed volumes for the three earth piles ranged from 8 to 16\% (Siebert and Teizer, 2014) indicating that the UAV could achieve a result comparable to that using more traditional methods. Aerial robots can supply many overlapping images, however, the vast volume of data collected means that currently the processing time remains a practical challenge which may be partly tackled by various filtering methods (Han et al. 2018).

\section{Robotic construction and repair}

Petersen et al. (2019) conducted a comprehensive review of collective robotic construction (CRC), incorporating structural and architectural design, construction procedure, scalability, and adaptability. They concluded that some fundamental challenges should be addressed to implement CRC in construction industry: (i) ‘robust autonomy’; (ii) ‘perception’; (iii) ‘reliable mechanisms'; and (iv) 'system integration’ (Petersen et al. 2019). Buchanan and Gardner (2019) conducted a broad review of metal 3D printing or additive manufacturing (AM) for robotic construction. They argued that powder bed fusion (PBF) and directed energy deposition (DED) methods are the most viable techniques for metal 3D printing as they allow more accurate construction although at a relatively high cost, build time and limitations on maximum size (Buchanan and Gardner, 2019). Hunt et al. (2014) and Dams et al. (2020) presented preliminary studies on the use of aerial 3D printing as a potential pre-cursor to robotic construction using UAVs. Hunt et al. (2014) discussed the design and classification of 3D printing of expanding polyurethane foam (EPF) in the context of using a UAV to create a structure or repair an existing structure. Chaltiel et al. (2018) and Stephanie et al. (2018) discuss using flying robots for mud shell fabrication using 'Bioshotcrete'.

The motivations for further uptake of aerial robotic technology in the construction sector include mainly improvements in safety. This is due to the better monitoring of people 
on building sites and avoiding the need for people to work at dangerous heights (or spaces) with the uptake of robots for construction of some components.

\section{POST DISASTER RESPONSE SURVEYS AND RAPID DAMAGE ASSESSMENT}

The uptake of UAVs by the military was partly due to ability to eliminate the risk associated with sending pilots into dangerous zones (cf. Hyunkyung et al. 2016). The same applies with humanitarian aid for disaster response efforts. In addition to reducing safety hazards, UAVs also accommodate the need for quick response, access to difficult areas and extensive information of the scene (at relatively low cost) (e.g., Daniel et al. 2009). UAVs can also monitor the progression of fires and floods (Casbeer et al. 2006; DeBell et al. 2015). Teams of UAVs are referred to 'Swarm systems’ (e.g., Hauert et al. 2009; Carrillo-Zapata et al. 2020). Robots operating in teams or as single units can provide real-time information, mapping support and media footage as well as perform infrastructure assessments, act as ad hoc communication networks, and identify victims of natural disasters who may be stranded or injured, direct them to safe locations or deliver medical supplies (Erdelj et al. 2017; Moloo, 2016; Recchiuto and Sgorbissa, 2019).

\section{Post-Disaster Response Assessments}

Ezequiel et al. (2014) discussed how UAVs can be used post-disaster to assess for example, the scale of governmental assistance needed; structural damages and damages to crops and vegetation (often a vital industry in less developed nations) and management of water resources. Rapid response after a disaster is critical, hence efficiency is key (Erdejl et al. 2017). UAVs can quickly obtain aerial imagery, which can be used to up-date hazard maps and develop dense surface and elevation models (Erdejl et al. 2017; Yamamoto et al. 2014). Postdisaster, dangerous obstacles can hinder human teams on the ground which can be avoided (as least partly) with the use of UAVs (Greenwood et al. 2019). UAVs can identify access routes 
and the worst affected regions meaning rescue efforts can be coordinated more effectively (Adams and Freidland, 2011; Erdejl et al. 2017). UAVs can also be used for rapid inspection of individual structures and bridges. For example, if a bridge or building is damaged during earthquake or fire after earthquake, it is not safe to be assessed by human inspectors in the field. SHM using UAV imagery can accelerate the inspection and reconstruction phases (Adams and Friedland, 2011; Erdejl et al. 2017; Yamamoto et al. 2014) as necessary data can be provided more quickly and safely. Pratt et al. (2008) investigated the Berkman Plaza collapse in Jacksonville in 2007 using a tethered UAV. Murphy et al. (2008) implemented a UAV to help navigate an Unmanned Sea-surface Vehicle (USV) as the communications link between the USV and controller.

If an area is deemed too dangerous to enter, UAVs can be very beneficial. This was the case in Fukushima, Japan (which experienced an earthquake followed by a tsunami in March 2011 (Norio et al. 2011)). The disaster disrupted a nuclear facility and the area had to be evacuated, making reconnaissance of the area incredibly difficult (Adams and Friedland, 2011; Norio et al. 2011). However, UAV surveillance of the facility was possible, and with additional sensors, the UAV could also collect information on the radiation being emitted without endangering humans (as outlined in Adams and Friedland, 2011).

\section{Monitoring Flood and Fire Risks}

UAVs can provide efficient and low-cost data collection for flood impact assessments to assign resources and aid (DeBell et al. 2015). UAVs have been used to aid firefighters in monitoring perimeters and assessing buildings (e.g., Casbeer et al. 2006; Merino et al. 2006; Stewart, 2017). Casbeer et al. (2006) presented a method using a team of UAVs to track the extent of a forest fire to provide close to real-time information to authorities. Similarly, Merino et al. (2006) presented a method for using a cooperative team of UAVs for detecting and confirming a fire location using visual and infrared images. Stewart (2017) discussed the Los Angeles Fire 
Department's method of fighting the Skirball fire in December 2017: one UAV tracked the fire path with visual images and a second UAV carried a thermal camera to help direct the firefighting effort (UAVs were used to survey damaged properties after the fire). UAV imagery also helped to assess the structural condition of the Grenfell tower in London before allowing firefighters into the building (Margaritoff, 2017).

The motivations for further uptake of aerial robotic technology for post-disaster response surveys as and post disaster rapid damage assessments include mainly 'improved measurement capability' and 'safety improvements'. UAVs can access dangerous areas post disaster where it may be dangerous for human inspectors to venture (e.g., flooded areas, places of potential radiation leakage, buildings that are on fire) as well as provide measurements and data that cannot be obtained with more conventional means e.g., manned aircraft or satellites.

\section{CONSTRAINTS ON WIDER IMPLEMENTATION}

Despite the many advantages that UAVs can offer to civil engineering, there are still many difficulties that must be overcome (summarised in Table 3).

\section{Legislation and Regulations}

The legislation surrounding UAV usage is another barrier to their implementation for civil engineering applications. The legislative environment must be considered, e.g., within the UK, a pilot must keep the UAV in their visible line of sight and additional permissions must be requested for beyond line-of-sight operations (see CAA, 2015). Frederiksen et al. (2019) identified that in Denmark drones cannot fly closer than $150 \mathrm{~m}$ to large public roads and centres of population without special permission. The strict legislation surrounding UAV use led McRobbie et al. (2015) to conclude that UAVs are not yet able to replace visual inspections. However, it could be posited that if UAV use were more widespread then organisations 
employing UAVs for civil use would be more equipped to both comply and shape such regulations.

Privacy is a major concern when employing UAVs (e.g., Finn and Wright, 2012; Herrmann, 2016; Luppicini and So 2016; Menouar et al. 2017; Erdelij et al. 2017; Frederiksen et al. 2019) and permission must be granted by the landowner or civil authority and any onsite employees before flights can take place (Herrmann, 2016; Frederiksen et al. 2019). Luppicini and So (2016) noted that civil uses of UAV technology are relatively new, and regulations and laws to protect against these issues have not yet been sufficiently developed and further research must be conducted to understand and mitigate the risks UAVs pose to privacy rights. There is a lack of international standardisation making UAV use in overseas projects complicated: in general, most countries restrict UAV operations over built-up areas and airports and require flight permissions to be acquired (e.g., DeBell et al. 2015). Both the UK Civil Aviation Authority (CAA) and the USA Federal Aviation Authority (FAA) also limit the height of UAV flights (cf. CAA, 2015; Mohammed et al. 2014). Many jurisdictions are willing to grant additional permissions to first responders (to disaster events) to rapidly assess the scale of the disaster (while noting that sensitive information should be immediately censored) (Erdejl et al. 2017).

\section{Weather Conditions}

Construction work and post disaster surveys are carried out in a wide variety of weather conditions and therefore it is essential that aerial robots used on construction sites remain usable during different seasons (Irizarry et al. 2012). UAV performance can be affected by weather, especially wind speeds and temperature (e.g., Siebert and Tezier, 2014; Ellenberg et al. 2015; DeBell et al. 2015; Omar and Nehdi, 2017; Greenwood et al. 2019). Bernard et al. (2011) commented that the wind gusts $(35 \mathrm{~km} / \mathrm{h})$ experienced by the UAV caused stress on the rotors if the pilot tried to compensate (noting also that if the motion was not compensated for 
this did not occur). Siebert and Teizer (2014) found that the wind caused the UAV to experience turbulences, resulting in some blurred images which had to be manually removed. UAVs are often required to hover during SHM work and wind can reduce the quality of the collected data (e.g., Ellenberg et al. 2015; Guerrero and Bestaoui, 2013). Pratt et al. (2008) found that with an air temperature of $2^{\circ} \mathrm{C}$, the UAV experienced communication issues and loss of control.

\section{Payload, Flight Endurance and Operation}

Commercial UAVs are often small and lightweight, with limited payload (Burgess, 2016; DeBell et al. 2015; Hern, 2017). Therefore, battery capacity is low, and the UAVs can often only fly for short times (about 15-30min) (e.g., Kardasz, et al. 2016; Omar and Nehdi, 2017; Menouar et al. 2017). Given the mobility, this flight time was considered adequate for data acquisition, or if more time was required, performing multiple trips was not a major inconvenience (cf. Gheisari and Esmaeili, 2016; Murphy et al. 2008; Siebert and Teizer, 2014). However, if UAVs were to be used in robotic construction, they need to have a nozzle to pour concrete or any other materials, which might exceed the vehicle's payload. Kang and Cha (2018b) also point out that in some areas the lack of Global Positioning System (GPS) may hinder UAV operation which may be mitigated by ultrasonic beacons. Bolourian and Hammad (2020) also point out that loss of GPS signal may be expected when UAVs flight under a bridge. In such instances, ground-based image capture systems may be needed (e.g., Popescu et al. 2019).

\section{Service Altitude}

UAV altitude requirements affects construction site management (e.g., Siebert and Teizer, 2014;) and disaster response (e.g., Pratt et al. 2008). Service altitudes may result in a necessary compromise between collecting higher resolution photos, or efficient data collection (Omar and Nehdi, 2017). Higher quality images are easier to obtain at lower altitudes, but this requires 
longer flight times (e.g., Siebert and Teizer, 2014). Reducing flight time with path planning to reduce total path length is an effective way to manage UAV endurance (e.g., Bolourian and Hammad 2020). Additionally, obstacle avoidance technology may be required, and images may be blurred if the UAV travels quickly (Adams and Friedland, 2011). Casbeer et al. (2006) investigated UAVs for fire surveillance e explaining that UAVs operating at low altitudes would be at elevated risk from the effects of the fire. However, in other situations, if there is low cloud cover, then the UAV may have to be flown at a lower altitude unless radar images are being obtained (Adams and Friedland, 2011).

\section{Lens Distortion}

To produce 3D reconstructions of structures, the curvature of the lens can lead to distortions which affect the quality of the models produced (Ellenberg et al. 2015; Lattanzi and Miller, 2015; Omar and Nehdi, 2017). These distortions can be reduced by ensuring the images were captured with the camera perpendicular to the image (Omar and Nehdi, 2017); with better choice of lens (Lattanzi and Miller, 2015) or by improved calibration processes to correct for lens distortion (Xu and Brownjohn, 2018). Other approaches include implementing an algorithm during the post processing of the photographs to remove the distortion (Ellenberg et al. 2015; Park et al. 2012).

\section{Data volume and Analysis}

As with much civil infrastructure monitoring the volume of data collected is a challenge and UAV based measurement platforms are no exception (e.g., Ham et al. 2016; Frederiksen et al. 2019). Targeted monitoring with a clear purpose and a realistic understanding of what monitoring can deliver is needed to avoid 'data overload'. This can lead to much data going unprocessed and unanalysed (monitoring for the sake of monitoring). The developing trends related to the use of Artificial Intelligence (AI) applications in the civil engineering space (e.g., 
Lu et al. 2012; Spencer et al. 2019) requires data to train such systems. Recent developments in deep learning algorithms such as SHMnet (Zhang et al. 2019) and the convolutional neural network (CNN) method (Cha et al. 2017) used Kang and Cha (2018b) for use in SHM may in the future mean that the challenge of data volume can be minimised.

\section{SUMMARY}

Aerial robotics has been the subject of considerable research for civil engineering application in recent years. To summarise: aerial robotic usage has potential in three broad areas of civil engineering: (i) Monitoring and inspection of civil infrastructure; (ii) Site management, robotic construction and maintenance; (iii) Post-disaster response surveys and rapid damage assessment. Table 4 shows the above three categories subdivided into the 'established' and ‘emerging' uses. When aerial platforms are used in a primarily surveillance capacity i.e. for tracking people and plant movements on construction sites, rapidly assessing extent of regional damage after disasters.

Aerial robots may improve efficiency (time and cost) of the aforementioned application categories (Table 4) as well as providing additional safety benefits for infrastructure inspectors and first responders in disaster-struck areas. However, the ethical concerns and legislation restricting their use, as well as the inability of UAVs to perform effectively in adverse weather, remain impediments to the expansion of their use in civil engineering applications. Future developments with swarm robotic systems and fully autonomous UAV systems may negate some of the need for licensed pilots. Further improvements with battery life and power systems may also lead to further uptake for complex monitoring tasks e.g., hovering at key locations near a bridge asset.

Based on the results of this review aerial robots are predominantly used by civil engineers for structural monitoring and construction management and is reasonably well 
established but the ability to reliably achieve ‘damage detection’ (see Webb et al. 2015) and change of condition remains a challenge, which is the case for all monitoring systems.

\section{ACKNOWLEDGEMENTS}

This work was partly funded by the Engineering and Physical Science Research Council (EPSRC) under the project "Seismic Safety and Resilience of Schools in Nepal” SAFER (EP/P028926/1). The first author thanks J M Freeman for his helpful discussions on the use of drone technology. The third author thanks Dr Sabine Hauert and Mr Julian Hird for their helpful discussions related to Swarm robotics. The authors thank the anonymous reviewers for their comments and suggestions which have helped improve the paper.

\section{DATA AVAILABILITY}

No new experimental data was produced during this research.

\section{REFERENCES}

Adams, S.M. and Friedland, C.J. (2011). A survey of Unmanned Aerial Vehicle (UAV) usage for imagery collection in disaster research and management. Paper Presented at the Ninth International Workshop on Remote Sensing for Disaster Response, Stanford, CA, USA.

Albeaino, G., Gheisari, M. and Franz, B. W. (2019). A systematic review of unmanned aerial vehicle application areas and technologies in the AEC domain. Journal of Information Technology in Construction, 24: 381-405, https://www.itcon.org/2019/20 [10 December 2020].

Alizadehsalehi, S., Yitmen, I., Celik, T. and Arditi, D. (2020). The effectiveness of an integrated BIM/UAV model in managing safety on construction sites. International Journal of Occupational Safety and Ergonomics, 26(4): 829-844, https://doi.org/10.1080/10803548.2018.1504487 
Bennetts, J., Denton, S. R., Webb, G. T., Nepomuceno, D. T. and Vardanega, P. J. (2021). Looking to the future of bridge inspection and management in the UK. In: Bridge Maintenance, Safety, Management, Life-Cycle Sustainability and Innovations: Proceedings of the 10th International Conference on Bridge Maintenance, Safety and Management (IABMAS 2020) (Yokota, H. and Frangopol, D.M. (eds.)). CRC Press, Boca Raton, FL, USA. In Press.

Bennetts, J., Vardanega, P. J., Taylor, C. A. and Denton, S. R. (2016). Bridge data - what do we collect and how do we use it? In: Transforming the Future of Infrastructure through Smarter Information: Proceedings of the International Conference on Smart Infrastructure and Construction, 27-29 June 2016. (Mair, R. J., Soga, K., Jin, Y., Parlikad, A. K. and Schooling, J. M. eds.) ICE Publishing, London, UK, pp. 531-536.

Bennetts, J., Vardanega, P. J., Taylor, C. A. and Denton, S. R. (2020). Survey on the use of data in UK bridge asset management. Proceedings of the Institution of Civil Engineers Bridge Engineering, 173(4): 211-222, https://doi.org/10.1680/jbren.18.00050

Bennetts, J., Webb, G., Denton, S., Vardanega, P. J. and Loudon, N. (2018). Quantifying Uncertainty in Visual Inspection Data. In: Maintenance, Safety, Risk, Management and Life-Cycle Performance of Bridges, (N. Powers, D. Frangopol, R. Al-Mahaidi, R. and C. Capriani (eds)) Taylor \& Francis, London, UK, pp. 2252-2259.

Bernard, M., Kondak, K., Maza, I. and Ollero, A. (2011). Autonomous transportation and deployment with aerial robots for search and rescue missions. Journal of Field Robotics, 28(6): 914-931, https://doi.org/10.1002/rob.20401

Bolourian, N. and Hammad, A. (2020). LiDAR-equipped UAV path planning considering potential locations of defects for bridge inspection. Automation in Construction, 117: [103250], https://doi.org/10.1016/j.autcon.2020.103250

Buchanan, C. and Gardner, L. (2019). Metal 3D printing in construction: A review of methods, research, applications, opportunities and challenges. Engineering Structures, 180: 332-348, https://doi.org/10.1016/j.engstruct.2018.11.045

Burgess, M. (2016). DHL's delivery drone can make drops quicker than a car. Wired. Available at: < https://www.wired.co.uk/article/dhl-drone-delivery-germany > [10 December 2020]

Canning, L. and Kashani, M. M. (2016). Assessment of U-type wrought iron railway bridges. Proceedings of the Institution of Civil Engineers - Engineering History and Heritage, 169(2): 58-67, https://doi.org/10.1680/jenhh.15.00017 
Carrillo-Zapata, D., Milner, E., Hird, J., Tzoumas, G., Vardanega, P.J., Sooriyabandara, M., Giuliani, M., Winfield, A.F.T. and Hauert, S. (2020). Mutual shaping in swarm robotics: User studies in fire and rescue, storage organisation, and bridge inspection. Frontiers in Robotics and AI, 7: [53], https://doi.org/10.3389/frobt.2020.00053

Casbeer, D. W., Kingston, D. B., Beard, R. W. and McLain, T. W. (2006). Cooperative forest fire surveillance using a team of small unmanned air vehicles. International Journal of Systems Science, 37(6): 351-360, https://doi.org/10.1080/00207720500438480

Cha, Y-J., Choi, W. and Büyüköztürk, O. (2017). Deep Learning-Based Crack Damage Detection Using Convolutional Neural Networks. Computer-Aided and Infrastructure Engineering, 32(5): 361-378, https://doi.org/10.1111/mice.12263

Chacon, R., Sanchez-Juny, M., Real, E., Gironella, X., Puigagut, J. and Ledesma, A. (2018). Digital twins in civil and environmental engineering classrooms. EUCEET 2018: 4th International Conference on Civil Engineering Education: Challenges for the Third Millennium. Barcelona: International Centre for Numerical Methods in Engineering (CIMNE) (Turmo, J. and Lozano, J.A. (eds.)), 10pp.

Chaltiel, S., Bravo, M., Goessens, S., Latteur, P., Mansouri, M. and Ahmad, I. (2018). Dry and Liquid clay mix drone spraying for Bioshotcrete. In: Proceedings of the IASS Symposium 2018 Creativity in Structural Design July 16-20, 2018, MIT, Boston, USA (Mueller, C. \& Adriaenssens, S. (eds.)). 8pp.

Chermprayong, P., Zhang, K., Xiao, F. and Kovac, M. (2019). An Integrated Delta Manipulator for Aerial Repair. IEEE Robotics and Automation Magazine, 26(1): 54-66, https://doi.org/10.1109/MRA.2018.2888911

Civil Aviation Authority (CAA) (2015). Unmanned Aircraft and Drones. Available at: $<$ https://www.caa.co.uk/Consumers/Unmanned-aircraft-and-drones/ $>$ [10 December 2020]

Clark, M. R., McCann, D. M. and Forde, M. C. (2003). Application of infrared thermography to the non-destructive testing of concrete and masonry bridges. NDT \& E International, 36(4): 265-275, https://doi.org/10.1016/S0963-8695(02)00060-9

Coifman, B., McCord, M., Mishalani, R. G., Iswalt, M. and Ji, M. (2006). Roadway traffic monitoring from an unmanned aerial vehicle. IEE Proceedings - Intelligent Transport Systems. 153(1): 11-20, https://doi.org/10.1049/ip-its:20055014

Collins, J., Ashurst, D., Webb, J., Sparkes, P. and Ghose, A. (2019). Guidance on hidden defects in bridges in the UK and Ireland. Proceedings of the Institution of Civil Engineers - Bridge Engineering, 171(1): 41-53, https://doi.org/10.1680/jbren.18.00021 
Dams, B., Sareh, S., Zhang, K., Shepherd, P., Kovac, M. and Ball, R. (2020). Aerial additive building manufacturing: three-dimensional printing of polymer structures using drones. Proceeding of the Institution of Civil Engineers - Construction Materials, 173(1): 3-14, https://doi.org/10.1680/jcoma.17.00013

Daniel, K., Dusza, B., Lewandowski, A. and Wietfeld, C. (2009). AirShield: A system-ofsystems MUAV remote sensing architecture for disaster response. Paper presented at the $20093^{\text {rd }}$ Annual IEEE Systems Conference, Vancouver, BC, Canada.

DeBell, L., Anderson, K., Brazier, R. E., King, N. and Jones, L. (2015). Water resource management at catchment scales using lightweight UAVs: current capabilities and future perspectives. Journal of Unmanned Vehicle Systems, 4(1): 7-30, https://doi.org/10.1139/juvs-2015-0026

Duque, L. Seo, J. and Wacker, J. (2018). Bridge Deterioration Quantification Protocol Using UAV. Journal of Bridge Engineering, 23(10): [04018080], https://doi.org/10.1061/(ASCE)BE.1943-5592.0001289

Ellenberg, A., Branco, L., Krick, A., Bartoli, I. and Kontsos, A. (2015). Use of Unmanned Aerial Vehicle for Quantitative Infrastructure Evaluation. Journal of Infrastructure Systems, 21(3): 04014054, https://doi.org/10.1061/(ASCE)IS.1943-555X.0000246

Erdelj, M., Natalizio, E., Chowdhury, K. R. and Akyildiz, I. F. (2017). Help from the sky: leveraging UAVs for disaster management. IEEE Pervasive Computing, 16(1): 24-32, https://doi.org/10.1109/MPRV.2017.11

Ezequiel, C. A. F., Cua, M., Libatique, N. C., Tangonan, G. L., Alampay, R., Labuguen, R. T., Favila, C. M., Honrado, J. L. E., Caños, V., Devaney, C., Loreto, A. B., Bacusmo, J. and Palma, B. (2014). UAV aerial imaging applications for post-disaster assessment, environmental management and infrastructure development. International Conference on Unmanned Aircraft Systems, 274-283, http://doi.org/10.1109/ICUAS.2014.6842266

Finn, R. L. and Wright, D. (2012). Unmanned aircraft systems: surveillance, ethics and privacy in civil applications. Computer Law \& Security Review, 28(2): 184-194, https://doi.org/10.1016/j.clsr.2012.01.005

Frederiksen, M. H., Mouridsen, O-A. V. and Knudsen, M. P. (2019). Drones for inspection of infrastructure: Barriers, opportunities and successful uses. University of Southern Denmark (SDU) Centre for Integrative Innovation Management, Available at: $<$ https://uasdenmark.dk/wp-content/uploads/2019/06/Final_InfrastructureMemo_30.05.2019.pdf $>$ [10 December 2020]. 
Freeman, M. R. (2018). Applications of UAVs in Civil Engineering: A Review. Undergraduate Research Report 1718RP031. Department of Civil Engineering, University of Bristol, Bristol, UK.

Ghahremani, K., Khaloo, A., Mohamaid, S. and Lattanzi, D. (2018). Damage Detection and Finite-Element Model Updating of Structural Components through Point Cloud Analysis. Journal of Aerospace Engineering, 31(5): [04018068], https://doi.org/10.1061/(ASCE)AS.1943-5525.0000885

Gheisari, M. and Esmaeili, B. (2016). Unmanned Aerial Systems (UAS) for Construction Safety Applications. Construction Research Congress 2016, 2642-2650, https://doi.org/10.1061/9780784479827.263

Giordan, D., Adams, M.S., Aicardi, I., Alicandro, M. Allasia, P., Baldo, M., De Berardinis, P., Dominici, D., Godone, D., Hobbs, P., Lechner, V., Niedzielski, T., Piras, M., Rotilio, M. Salvini, R., Segor, V., Sotier, B. and Troilo, F. (2020). The use of unmanned aerial vehicles (UAVs) for engineering geology applications. Bulletin of Engineering Geology and the Environment, 79(7): 3437-3481, https://doi.org/10.1007/s10064-020-01766-2

Greenwood, W. W., Lynch, J.P. and Zekkos, D. (2019). Applications of UAVs in Civil Infrastructure. Journal of Infrastructure Systems, 25(2): [04019002], https://doi.org/10.1061/(ASCE)IS.1943-555X.0000464

Guerrero, J. A. and Bestaoui, Y. (2013). UAV Path Planning for Structure Inspection in Windy Environments. Journal of Intelligent \& Robotic Systems, 69(1): 297-311, https://doi.org/10.1007/s10846-012-9778-2

Ham, Y., Han, K. K., Lin, J. J. and Golparvar-Fard, M. (2016). Visual monitoring of civil infrastructure systems via camera-equipped Unmanned Aerial Vehicles (UAVs): a review of related works. Visualization in Engineering, 4: [1], https://doi.org/10.1186/s40327-015$\underline{0029-\mathrm{Z}}$

Han, K., Degol, J. and Golparvar-Fard, M. (2018). Geometry- and appearance-based reasoning of construction progress monitoring. Journal of Construction Engineering and Management, 144(2): [04017110], https://doi.org/10.1061/(ASCE)CO.1943$\underline{7862.0001428}$

Hauert, S. (2016). Building a Startup Ecosystem for Robotics in Europe [Industrial Activities]. IEEE Robotics \& Automation Magazine, 23(3): 14-16, https://doi.org/10.1109/MRA.2016.2588003 
Hauert, S. Zuffery, J.-C. and Floreano, D. (2009). Evolved swarming without positioning information: an application in aerial communications relay. Autonomous Robots, 26(1): 21-32, https://doi.org/10.1007/s10514-008-9104-9

Hellmuth, J., Hunter, A. and Barclay, A. (2018). Unmanned Aerial Vehicles (UAV) and their continuing application to geotechnical slope risk assessment and design. Australian Geomechanics, 53(3): 41-49.

Hern, A. (2016). Amazon claims first successful Prime Air drone delivery. The Guardian Available at: < https://www.theguardian.com/technology/2016/dec/14/amazon-claimsfirst-successful-prime-air-drone-delivery > [10 December 2020]

Herrmann, M. (2016). Unmanned Aerial Vehicles in Construction: An Overview of Current and Proposed Rules. Construction Research Congress 2016, 588-596, https://doi.org/10.1061/9780784479827.060

Hui, L., Park, M.-W. and Brilakis, I. (2015). Automated Brick Counting for Façade Construction Progress Estimation. Journal of Computing in Civil Engineering, 29(6): [04014091], https://doi.org/10.1061/(ASCE)CP.1943-5487.0000423

Hunt, G., Mitzalis, F., Alhinai, T., Hooper, P. A. and Kovač, M. (2014). 3D Printing with Flying Robots. IEEE International Conference on Robotics and Automation (ICRA), Hong Kong Convention and Exhibition Center, May 31-June 7, 2014, Hong Kong, China. https://doi.org/10.1109/ICRA.2014.6907515

Hyunkyung, M., Hayoung, J. and Euiho, S. (2016). An Analysis for Measure of Effectiveness of an Unmanned Aerial Vehicle Using Simulation. Journal of Engineering and Technology, 5(3): 69-82.

Irizarry, J. and Costa, D. B. (2016). Exploratory Study of Potential Applications of Unmanned Aerial Systems for Construction Management Tasks. Journal of Management in Engineering, 32(3): [05016001], https://doi.org/10.1061/(ASCE)ME.1943$\underline{5479.0000422}$

Irizarry, J., Gheisari, M. and Walker, B. (2012). Usability assessment of drone technology as safety inspection tools. Journal of Information Technology in Construction, 17: 194-212, Available at: < http://www.itcon.org/2012/12 > [10 December 2020].

Kaamin, M., Razali, S. N. M., Ahmad, N. F. A., Bukari, S. M., Ngadiman, N., Kadir, A. A. and Hamid, N. B. (2017). The application of micro UAV in construction project. AIP Conference Proceedings, 1891(1): [020070], https://doi.org/10.1063/1.5005403 
Kaaniche, K., Champion, B., Pegard, C. and Vasseur, P. (2005). A Vision Based Algorithm for Dynamic Detection of Moving Vehicles with a UAV. Proceedings of the 2005 IEEE International Conference on Robotics and Automation, 1878-1883, https://doi.org/10.1109/ROBOT.2005.1570387

Kaewunruen, S. and Xu, N. (2018). Digital Twin for Sustainability Evaluation of Railway Station Buildings. Frontiers of Built Environment, 4: [77], https://doi.org/10.3389/fbuil.2018.00077

Kang, D. and Cha, Y-J. (2018a). Damage detection with an autonomous UAV using deep learning. In: Proceedings SPIE 10598, Sensors and Smart Structures Technologies for Civil, Mechanical, and Aerospace Systems 2018, 1059804, https://doi.org/10.1117/12.2295961

Kang, D. and Cha, Y-J. (2018b). Autonomous UAVs for Structural Health Monitoring Using Deep Learning and an Ultrasonic Beacon System with Geo-Tagging. Computer-Aided Civil Infrastructure Engineering, 33(10): 885-902, https://doi.org/10.1111/mice.12375

Kardasz, P., Doskocz, J., Hejduk, M., Wiejkut, P. and Zarzycki, H. (2016). Drones and Possibilities of Their Using. Journal of Civil \& Environmental Engineering, 6: 233, http://dx.doi.org/10.4172/2165-784X.1000233

Kashani, M., Maddocks, J. and Afsar Dizaj, E. (2019). Residual capacity of corroded reinforced concrete bridge components: a state-of-the-art review. Journal of Bridge Engineering, 24(7): [03119001], https://doi.org/10.1061/(ASCE)BE.1943-5592.0001429

Kaya, Y., Ventura, C., Huffman, S. and Turek, M. (2017). British Columbia Smart Infrastructure Monitoring System. Canadian Journal of Civil Engineering, 44(8): 579588, https://doi.org/10.1139/cjce-2016-0577

Khaloo, A., Lattanzi, D. and Jachimowicz, A. (2018a). Utilizing UAV and 3D Computer Vision for Visual Inspection of a Large Gravity Dam. Frontiers in Built Environment, 4: [31], https://doi.org/10.3389/fbuil.2018.00031

Khaloo, A., Lattanzi, D., Cunningham, K., Dell’Andrea, R. and Riley, M. (2018b). Unmanned aerial vehicle inspection of the Placer River Trail Bridge through image-based 3D modelling. Structure and Infrastructure Engineering, 14(1): 124-136, https://doi.org/10.1080/15732479.2017.1330891

Laschi, C., Mazzolai, B., Nosengo, N., Cave, V. D., Asfour, T., Floreano, D., Stramigioli, S., Laumond, J-P. and Hauert, S. (2018). The Rise of the Robots: The European Robotics Flagship [Regional Spotlight]. IEEE Robotics \& Automation Magazine, 25(4): 121-122, https://doi.org/10.1109/MRA.2018.2874794 
Lattanzi, D. and Miller, G. R. (2014). Robust Automated Concrete Damage Detection Algorithms for Field Applications. Journal of Computing in Civil Engineering, 28(2): 253-262, https://doi.org/10.1061/(ASCE)CP.1943-5487.0000257

Lattanzi, D. and Miller, G. R. (2015). 3D Scene Reconstruction for Robotic Bridge Inspection. Journal of Infrastructure Systems, 21(2): [04014041], https://doi.org/10.1061/(ASCE)IS.1943-555X.0000229

Lattanzi, D., Miller, G. R., Eberhard, M. O. and Haraldsson, O. S. (2016). Bridge column maximum drift estimation via computer vision. Journal of Computing in Civil Engineering, 30(4): [04015051], https://doi.org/10.1061/(ASCE)CP.1943-5487.0000527

Lattanzi, D. and Miller, G. (2017). Review of Robotic Infrastructure Inspection Systems. Journal of Infrastructure Systems, 23(3): [04017004], https://doi.org/10.1061/(ASCE)IS.1943-555X.0000353

Liu, P., Chen, A. Y., Huang, Y.-N., Han, J.-Y., Lai, J.-S., Kang, S.-C., Wu, T.-H, Wen, M.-H. and Tsai, M.-H. (2014). A review of rotorcraft Unmanned Aerial Vehicle (UAV) developments and applications in civil engineering. Smart Structures and Systems, 13(6): 1065-1094, http://doi.org/10.12989/sss.2014.13.6.1065

Lu, P., Chen, S. and Zheng, Y. (2012). Artificial Intelligence in Civil Engineering. Mathematical Problems in Engineering, 2012: [145974], https://doi.org/10.1155/2012/145974

Luppicini, R. and So, A. (2016). A technoethical review of commercial drone use in the context of governance, ethics, and privacy. Technology in Society, 46: 109-119, https://doi.org/10.1016/j.techsoc.2016.03.003

Margaritoff, M. (2017). A drone helped firefighters combat the London Grenfell Tower inferno. The Drive. Available at: $<$ http://www.thedrive.com/aerial/11701/a-drone-helpedfirefighters-combat-the-london-grenfell-tower-inferno $>$ [10 December 2020]

Martínez, C., Mondragûn, I. F., Olivares-Mèndez, M. A. and Campoy, P. (2011). On-board and Ground Visual Pose Estimation Techniques for UAV Control. Journal of Intelligent \& Robotic Systems, 61(1): 301-320, https://doi.org/10.1007/s10846-010-9505-9

McRobbie, S. G., Wright, M. A. and Chan, A. (2015). Can technology improve routine visual bridge inspections? Proceedings of the Institution of Civil Engineers - Bridge Engineering, 168(3): 197-207, https://doi.org/10.1680/jbren.12.00022 
Menouar, H., Guvenc, I., Akkaya, K., Uluagac, A. S., Kadri, A. and Tuncer, A. (2017). UAV-Enabled Intelligent Transportation Systems for the Smart City: Applications and Challenges. IEEE Communications Magazine, 55(3): 22-28, https://doi.org/10.1109/MCOM.2017.1600238CM

Merino, L., Caballero, F., Martinez-de Dios, J. R., Ferruz, J. and Ollero, A. (2006). A cooperative perception system for multiple UAVs: application to automatic detection of forest fires. Journal of Field Robotics, 23(3/4): 165-184, https://doi.org/10.1002/rob.20108

Mohammed, F., Idries, A., Mohamed, N., Al-Jaroodi, J. and Jawhar, I. (2014). UAVs for smart cities: Opportunities and challenges. Paper presented at the 2014 International Conference on Unmanned Aircraft Systems (ICUAS), 267-273, https://doi.org/10.1109/ICUAS.2014.6842265

Moloo, A. (2016). Human rabies: better coordination and emerging technology to improve access to vaccines. World Health Organization. Available at:

$<$ http://www.who.int/neglected_diseases/news/human_rabies_better_coordination_and_e merging technology/en// $>$ [10 December 2020]

Murphy, R. R., Steimle, E., Griffin, C., Cullins, C., Hall, M. and Pratt, K. (2008). Cooperative use of unmanned sea surface and micro aerial vehicles at Hurricane Wilma. Journal of Field Robotics, 25(3): 164-180, https://doi.org/10.1002/rob.20235

Norio, O., Ye, T., Kajitani, Y., Shi, P. and Tatano, H. (2011). The 2011 eastern Japan great earthquake disaster: Overview and comments. International Journal of Disaster Risk Science, 2(1): 34-42, https://doi.org/10.1007/s13753-011-0004-9

Omar, T. and Nehdi, M. L. (2017). Remote sensing of concrete bridge decks using unmanned aerial vehicle infrared thermography. Automation in Construction, 83: 360-371, https://doi.org/10.1016/j.autcon.2017.06.024

Park, J., Im, S., Lee, K.-H. and Lee, J.-O. (2012). Vision-Based SLAM System for Small UAVs in GPS-Denied Environments. Journal of Aerospace Engineering, 25(4): 519-529, https://doi.org/10.1061/(ASCE)AS.1943-5525.0000160

Petersen, K. H., Napp, N., Stuart-Smith, R., Rus, D. and Kovac, M. (2019). A review of collective robotic construction. Science Robotics, 4(28): [eaau8479], https://doi.org/10.1126/scirobotics.aau8479

Popescu, C., Täljsten, B., Blanksvärd, T. and Elfgren, L. (2019). 3D reconstruction of existing concrete bridges using optical methods, Structure and Infrastructure Engineering, 15(7): 912-924, https://doi.org/10.1080/15732479.2019.1594315 
Pratt, K. S., Murphy, R. R., Burke, J. L., Craighead, J., Griffin, C. and Stover, S. (2008). Use of Tethered Small Unmanned Aerial System at Berkman Plaza II Collapse. IEEE International Workshop on Safety, Security and Rescue Robotics, Sendai, Japan. https://doi.org/10.1109/SSRR.2008.4745890

Rathinam, S., Kim, Z. W. and Sengupta, R. (2008). Vision-Based Monitoring of Locally Linear Structures Using an Unmanned Aerial Vehicle. Journal of Infrastructure Systems, 14(1): 52-63, https://doi.org/10.1061/(ASCE)1076-0342(2008)14:1(52)

Reagan, D. (2017). Unmaned Aerial Vehicle Measurement Using Three-Dimensional Digital Image Correlation to Perform Bridge Structural Health Monitoring. M.S. thesis, University of Massachusetts Lowell, Lowell, MA.

Reagan, D., Sabato, A. and Niezrecki, C. (2017). Unmanned aerial vehicle acquisition of three-dimensional digital image correlation measurements for structural health monitoring of bridges. SPIE Smart Structures and Materials + Nondestructive. Evaluation and Health Monitoring, 1016909, https://doi.org/10.1117/12.2259985

Recchiuto, C. T. and Sgorbissa, A. (2018). Post-disaster assessment with unmanned aerial vehicles: A survey on practical implementation and research approaches. Journal of Field Robotics, 35(4): 459-490, https://doi.org/10.1002/rob.21756

Shakhatreh, H., Sawalmeh, A. H., Al-Fuqaha, A., Dou, Z. Almaita, E., Khalil, I., Othman, N. S., Khreishah, A. and Guizani, M. (2019). Unmanned Aerial Vehicles (UAVs): A Survey on Civil Applications and Key Research Challenges. IEEE Access, 7: 48572-48634, https://doi.org/10.1109/ACCESS.2019.2909530

Siddall, R., Ortega Ancel, A. and Kovač, M. (2017). Wind and water tunnel testing of a morphing aquatic micro air vehicle. Interface Focus, 7: 20160085, https://doi.org/10.1098/rsfs.2016.0085

Siebert, S. and Teizer, J. (2014). Mobile 3D mapping for surveying earthwork projects using an Unmanned Aerial Vehicle (UAV) system. Automation in Construction, 41(Supplement C): 1-14, https://doi.org/10.1016/j.autcon.2014.01.004

Smith, K. (2018). Self-repairing cities: Leeds’ quest for an autonomous-robot maintenance army. Construction Research and Innovation, 9(4): 91-94, https://doi.org/10.1080/20450249.2018.1556500

Snook, V. (2018) Using drone surveys of infrastructure and plant to improve safety and productivity. Proceedings of the Institution of Civil Engineers - Civil Engineering, 171(2): 53, https://doi.org/10.1680/jcien.2018.171.2.53 
Spencer, B. F., Hoskere, V. and Narazaki, Y. (2019). Advances in Computer Vision-Based Civil Infrastructure Inspection and Monitoring. Engineering, 5(2):199-222, https://doi.org/10.1016/j.eng.2018.11.030

Stephanie, C., Maite, B. and Abdullah, I. (2018). Adaptive Strategies for Mud Shell Robotic Fabrication. International Journal of Environmental Science \& Sustainable Development, 3(2): 64 -74, https://doi.org/10.21625/essd.v3iss2.382

Stewart, J. (2017). Drones take off in the battle against the Los Angeles fires. Wired. Available at: < https://www.wired.com/story/drones-take-off-in-the-battle-against-the-losangeles-fires/ > [10 December 2020]

Stewart, D. L., Follas, H., Knott, D. L. and Delport, T. (2018). Use of small unmanned aerial vehicles and related digital data in geotechnical and natural hazard impact assessments. Australian Geomechanics, 53(3): 23-38.

Teng, G. E., Zhou, M., Li, C. R., Wu, H. H., Li, W., Meng, F. R., Zhou, C. C. and Ma, L. (2017). Mini-UAV Lidar For Power Line Inspection. The International Archives of the Photogrammetry, Remote Sensing and Spatial Information Sciences, Volume XLII-2/W7, 2017 ISPRS Geospatial Week 2017, 18-22 September 2017, Wuhan, China, 297-300, https://doi.org/10.5194/isprs-archives-XLII-2-W7-297-2017

Thoeni, K., Santise, M., Guccione, D. E., Fityus, S., Roncella, R. and Giacomini, A. (2018). Use of low-cost terrestrial and aerial imagine sensors for geotechnical applications. Australian Geomechanics, 53(3): 101-122.

Thusyanthan, I., Blower, T. and Cleverly, W. (2017). Innovative uses of thermal imaging in civil engineering. Proceedings of the Institution of Civil Engineers - Civil Engineering, 170(2): 81-87, https://doi.org/10.1680/jcien.16.00014

Tomiczek, A. P., Whitley, T. J., Bridge, J. A. and Ifju, P. G. (2019). Bridge Inspections with Small Unmanned Aircraft Systems: Case Studies. Journal of Bridge Engineering, 24(4): [05019003], https://doi.org/10.1061/(ASCE)BE.1943-5592.0001376

Vaghefi, K., Oats, R., Harris, D., Ahlborn, T., Brooks, C., Endsley, A., Roussi, C., Shuchman, R., Burns, J. and Dobson, R. (2012). Evaluation of Commercially Available Remote Sensors for Highway Bridge Condition Assessment. Journal of Bridge Engineering, 17(6): 886-895, https://doi.org/10.1061/(ASCE)BE.1943-5592.0000303 Webb, G. T., Vardanega, P. J. and Middleton, C. R. (2015). Categories of SHM Deployments: Technologies and Capabilities. Journal of Bridge Engineering, 20(11): [04014118]. http://doi.org/10.1061/(ASCE)BE.1943-5592.0000735 
Wen, M.-C. and Kang, S.-C. (2014). Augmented Reality and Unmanned Aerial Vehicle Assist in Construction Management. 2014 International Conference on Computing in Civil and Building Engineering, 1570-1577, https://doi.org/10.1061/9780784413616.195

Wu, J. and Zhou, G. (2006). Real-Time UAV Video Processing for Quick- Response to Natural Disaster. Paper presented at the 2006 IEEE International Symposium on Geoscience and Remote Sensing, 976-979, https://doi.org/10.1109/IGARSS.2006.251

Xu, Y. and Brownjohn, J. (2018). Review of machine-vision based methodologies for displacement measurement in civil structures. Journal of Civil Structural Health Monitoring, 8(1): 91-110, https://doi.org/10.1007/s13349-017-0261-4

Yamamoto, T., Kusumoto, H. and Banjo, K. (2014). Data Collection System for a Rapid Recovery Work: Using Digital Photogrammetry and a Small Unmanned Aerial Vehicle (UAV). International Conference on Computing in Civil and Building Engineering, 875882, https://doi.org/10.1061/9780784413616.109

Zhang, T., Biswal, S. and Wang, Y. (2019). SHMnet: Conditional assessment of bolted connection with beyond human level performance. Structural Health Monitoring, https://doi.org/10.1177/1475921719881237

Zhou, S and Gheisari, M. (2018). Unmanned aerial system applications in construction: a systematic review. Construction Innovation, 18(4): 453-468, https://doi.org/10.1108/CI$\underline{02-2018-0010}$ 
Table 1: Summary of past review articles related to aerial robotics

\begin{tabular}{|c|c|c|}
\hline Reference & Identified use domains/categories & $\begin{array}{l}\text { Overall Review } \\
\text { focus }\end{array}$ \\
\hline $\begin{array}{l}\text { Adams and } \\
\text { Friedland } \\
\text { (2011) }\end{array}$ & $\begin{array}{l}\text { ‘Data Acquisition for Post-disaster Assessments' } \\
\text { 'Data Acquisition for Rapid Response' } \\
\text { 'Data Acquisition for Management and Monitoring' }\end{array}$ & $\begin{array}{l}\text { Disaster } \\
\text { management }\end{array}$ \\
\hline $\begin{array}{l}\text { Liu et al. } \\
\text { (2014) }\end{array}$ & $\begin{array}{l}\text { 'Seismic risk assessment' } \\
\text { 'Transportation' } \\
\text { 'Disaster Response' } \\
\text { 'Construction management' } \\
\text { 'Surveying and mapping' } \\
\text { 'Flood monitoring and assessment' }\end{array}$ & $\begin{array}{l}\text { General civil } \\
\text { engineering } \\
\text { applications }\end{array}$ \\
\hline $\begin{array}{l}\text { Mohammed } \\
\text { et al. (2014) }\end{array}$ & $\begin{array}{l}\text { 'Geospatial and Surveying Activities' } \\
\text { 'Civil Security Control' } \\
\text { 'Traffic and Crowd Management' } \\
\text { 'Natural Disaster Control and Monitoring' } \\
\text { 'Agriculture and Environmental Management' } \\
\text { 'Urban Security Increasing the city’s attractiveness' } \\
\text { 'Big Data Processing' } \\
\text { 'Coordination between heterogeneous systems' }\end{array}$ & Smart cities \\
\hline $\begin{array}{l}\text { Ham et al. } \\
(2016)\end{array}$ & $\begin{array}{l}\text { 'Construction and building performance monitoring' } \\
\text { 'Civil infrastructure condition assessment' }\end{array}$ & $\begin{array}{l}\text { Civil Infrastructure } \\
\text { Systems }\end{array}$ \\
\hline $\begin{array}{l}\text { Erdelj et al. } \\
\text { (2017) }\end{array}$ & $\begin{array}{l}\text { 'Monitoring, forecasting, and early warnings' } \\
\text { 'Disaster information fusion and sharing' } \\
\text { 'Situational awareness and logistics and evacuation } \\
\text { support' } \\
\text { 'Standalone communication system' } \\
\text { 'SAR missions' } \\
\text { 'Damage Assessment' }\end{array}$ & $\begin{array}{l}\text { Disaster } \\
\text { Management }\end{array}$ \\
\hline $\begin{array}{l}\text { Lattanzi and } \\
\text { Miller } \\
\text { (2017) }\end{array}$ & $\begin{array}{l}\text { 'bridge and tunnel inspection' } \\
\text { 'storage tank inspection' } \\
\text { 'postdisaster inspection and assessment' } \\
\text { 'miscellaneous applications' }\end{array}$ & $\begin{array}{l}\text { Robotic } \\
\text { Infrastructure } \\
\text { Inspection }\end{array}$ \\
\hline $\begin{array}{l}\text { Menour et } \\
\text { al. (2017) }\end{array}$ & $\begin{array}{l}\text { 'Flying Accident Report Agent' } \\
\text { 'Flying Roadside Unit' } \\
\text { 'Flying Police Eye' } \\
\text { Intelligent Transport Systems (ITS) Applications }\end{array}$ & $\begin{array}{l}\text { Transport Systems } \\
\text { for Smart Cities }\end{array}$ \\
\hline $\begin{array}{l}\text { Snook } \\
(2018)\end{array}$ & $\begin{array}{l}\text { 'Bridge and road surveys' } \\
\text { 'Inspecting plant at height' }\end{array}$ & $\begin{array}{l}\text { Condition surveys of } \\
\text { infrastructure and } \\
\text { plant }\end{array}$ \\
\hline $\begin{array}{l}\text { Zhou and } \\
\text { Gheisari } \\
\text { (2018) }\end{array}$ & $\begin{array}{l}\text { 'building inspection' } \\
\text { ‘damage assessment' } \\
\text { 'site surveying and mapping' } \\
\text { 'safety inspection' } \\
\text { 'progress monitoring' } \\
\text { 'others' }\end{array}$ & Construction \\
\hline $\begin{array}{l}\text { Albeanio et } \\
\text { al. (2019) }\end{array}$ & $\begin{array}{l}\text { 'Structural and infrastructure inspection' } \\
\text { 'Transportation' } \\
\text { 'Cultural heritage conservation' }\end{array}$ & $\mathrm{AEC}^{1}$ domain \\
\hline
\end{tabular}




\begin{tabular}{|c|c|c|}
\hline & $\begin{array}{l}\text { 'City and urban planning' } \\
\text { 'Progress monitoring' } \\
\text { 'Post-disaster assessment' } \\
\text { 'Construction safety' }\end{array}$ & \\
\hline $\begin{array}{l}\text { Frederiksen } \\
\text { et al. (2019) }\end{array}$ & $\begin{array}{l}\text { Inspecting: } \\
\text { 'roads and railroads' } \\
\text { 'electricity supply' } \\
\text { 'heating supply' }\end{array}$ & $\begin{array}{l}\text { Infrastructure } \\
\text { Inspection }\end{array}$ \\
\hline $\begin{array}{l}\text { Greenwood } \\
\text { et al. (2019) }\end{array}$ & $\begin{array}{l}\text { 'Monitoring of Infrastructure System Components' } \\
\text { 'Construction Safety and Progress Monitoring' } \\
\text { 'Geological and Geotechnical Engineering' } \\
\text { 'Post-Disaster Reconnaissance' }\end{array}$ & Civil Infrastructure \\
\hline $\begin{array}{l}\text { Shakhatreh } \\
\text { et al. (2019) }\end{array}$ & $\begin{array}{l}\text { 'Search and Rescue (SAR)' } \\
\text { 'Remote Sensing' } \\
\text { 'Construction \& Infrastructure Inspection' } \\
\text { 'Precision Agriculture' } \\
\text { 'Delivery of Goods' } \\
\text { 'Real-time Monitoring of Road Traffic' } \\
\text { 'Surveillance Applications of UAVs' } \\
\text { 'Providing Wireless Coverage' }\end{array}$ & $\begin{array}{l}\text { Civil applications } \\
\text { (as opposed to } \\
\text { military) }\end{array}$ \\
\hline $\begin{array}{l}\text { Giordan et } \\
\text { al. (2020) }\end{array}$ & $\begin{array}{l}\text { 'The use of UAV on landslides' } \\
\text { 'UAV for debris flow mapping and analysis' } \\
\text { 'The use of UAV for rock mass classification and } \\
\text { structural analysis' } \\
\text { 'Main applications of UAV in hydrology' } \\
\text { 'The use of UAV for glacier monitoring } \\
\text { and glacial' }{ }^{2} \text { outburst flood risk mitigation' } \\
\text { 'The smart management of building sites in a post- } \\
\text { seismic scenario using UAV photogrammetry' }\end{array}$ & $\begin{array}{l}\text { Engineering } \\
\text { Geology }\end{array}$ \\
\hline
\end{tabular}


Table 2: Areas for use of Aerial Robotics in civil engineering

\begin{tabular}{|c|c|}
\hline cation Category & Key References \\
\hline $\begin{array}{l}\text { Monitoring and } \\
\text { inspection of civil } \\
\text { infrastructure }\end{array}$ & $\begin{array}{l}\text { Coifman et al., (2006); Rathinam et al., (2008); Vaghefi et } \\
\text { al., (2012); Guerrero and Bestaoui, (2013); Lattanzi and } \\
\text { Miller, (2015); DeBell et al., (2015); Ellenberg et al., (2015); } \\
\text { Ham et al. (2016); Omar and Nehdi, (2017); Reagan, (2017); } \\
\text { Reagan et al., (2017); Teng et al., (2017); Hellmuth et al., } \\
\text { (2018); Khaloo et al., (2018a, 2018b); Stewart et al., (2018); } \\
\text { Duque et al., (2018); Kang and Cha (2018a, 2018b); } \\
\text { Frederiksen et al., (2019); Tomiczek et al., (2019); } \\
\text { Bolourian and Hammad (2020). }\end{array}$ \\
\hline $\begin{array}{l}\text { Site management, } \\
\text { robotic construction and } \\
\text { maintenance }\end{array}$ & $\begin{array}{l}\text { Irizarry et al., (2012); Hunt et al., (2014); Siebert and } \\
\text { Tiezer, (2014); Wen and Kang, (2014); Gheisari and } \\
\text { Esmaeili, (2016); Irizarry and Costa, (2016); Kaamin et al., } \\
\text { (2017); Smith (2018); Chaltiel et al., (2018); Stephanie et } \\
\text { al. (2018); Han et al., (2018); Alizadehsalehi et al., (2020); } \\
\text { Chermprayong et al., (2019); Peterson et al., (2019); Dams } \\
\text { et al., (2020). }\end{array}$ \\
\hline $\begin{array}{l}\text { Post-disaster response } \\
\text { surveys and rapid } \\
\text { damage assessments }\end{array}$ & $\begin{array}{l}\text { Casbeer et al., (2006); Merino et al., (2006); Wu and Zhou, } \\
\text { (2006); Murphy et al., (2008); Pratt et al., (2008); Daniel et } \\
\text { al., (2009); Adams and Friedland, (2011); Bernard et al., } \\
\text { (2011); Ezequiel et al., (2014); Yamamoto et al., (2014); } \\
\text { Erdejl et al., (2017); Recciuto and Sgorbissa, (2018). }\end{array}$ \\
\hline
\end{tabular}


Table 3: Summary of barriers to UAV uptake in civil engineering

\begin{tabular}{|l|l|}
\hline \multicolumn{1}{|c|}{ Barrier } & \multicolumn{1}{|c|}{ Example References } \\
\hline Legislation and Regulations & Herrmann (2016); Luppicini and So (2016) \\
\hline Weather conditions & $\begin{array}{l}\text { DeBell et al. (2015); Ellenberg et al. (2015); } \\
\text { Pratt et al. (2008) }\end{array}$ \\
\hline $\begin{array}{l}\text { Flight endurance issues such as: limited } \\
\text { battery life; payload or lack of GPS signal } \\
\text { during operation }\end{array}$ & $\begin{array}{l}\text { Gheisari and Esmaeili, (2016); Siebert and } \\
\text { Teizer (2014); Kang and Cha (2018b); } \\
\text { Frederiksen et al. (2019); Bolourian and }\end{array}$ \\
\hline Limits on service altitude & $\begin{array}{l}\text { Adams and Friedland (2011); Omar and } \\
\text { Nehdi (2017) }\end{array}$ \\
\hline Lens distortion & Park et al. (2012); Lattazi and Miller (2015) \\
\hline Large volumes of data to process and analyse & Ham et al. (2016); Frederiksen et al. (2019) \\
\hline
\end{tabular}


Table 4: Categorisation of aerial robotic application areas in civil engineering

\begin{tabular}{|c|c|c|c|}
\hline $\begin{array}{l}\text { Category } \\
\text { Number }\end{array}$ & $\begin{array}{l}\text { Application } \\
\text { Category }\end{array}$ & $\begin{array}{l}\text { Application Sub- } \\
\text { Categories }\end{array}$ & $\begin{array}{c}\text { Comments on current and future } \\
\text { uptake }\end{array}$ \\
\hline \multirow[t]{2}{*}{$\mathrm{I}$} & \multirow[t]{2}{*}{$\begin{array}{l}\text { Monitoring and } \\
\text { inspection of civil } \\
\text { infrastructure }\end{array}$} & $\begin{array}{l}\text { IA Inspection of } \\
\text { civil infrastructure }\end{array}$ & $\begin{array}{l}\text { Emerging - Aerial robots can take } \\
\text { photographs of structures to assist } \\
\text { with developing digital models. It } \\
\text { is unclear if a detailed visual } \\
\text { inspection of an infrastructure asset } \\
\text { (e.g. a bridge) could be carried out } \\
\text { only with robotic technology. } \\
\text { Ideally the robotic technology } \\
\text { should be able to fly or access all } \\
\text { parts of the asset. }\end{array}$ \\
\hline & & $\begin{array}{l}\text { IB Monitoring of } \\
\text { civil infrastructure }\end{array}$ & $\begin{array}{l}\text { Emerging - In many cases 'damage } \\
\text { detection' the aim of the study. } \\
\text { Webb et al. (2015) explains that } \\
\text { 'damage detection' is arguably the } \\
\text { most useful category of Structural } \\
\text { Health Monitoring but remains the } \\
\text { most challenging to successfully } \\
\text { achieve in practice. Detection of } \\
\text { the rate of change is difficult with } \\
\text { current visual inspection regimes } \\
\text { (Bennetts et al. 2020). }\end{array}$ \\
\hline \multirow[t]{2}{*}{ II } & \multirow{2}{*}{$\begin{array}{l}\text { Site management } \\
\text { and robotic } \\
\text { construction and } \\
\text { maintenance }\end{array}$} & $\begin{array}{c}\text { IIA Site } \\
\text { Management }\end{array}$ & $\begin{array}{l}\text { Established - tracking people and } \\
\text { plant movements now possible }\end{array}$ \\
\hline & & $\begin{array}{c}\text { IIB Robotic } \\
\text { construction and } \\
\text { maintenance }\end{array}$ & $\begin{array}{l}\text { Emerging - applications still } \\
\text { limited by payload and flight } \\
\text { endurance. }\end{array}$ \\
\hline \multirow[t]{2}{*}{ III } & \multirow[t]{2}{*}{$\begin{array}{c}\text { Post-disaster } \\
\text { response surveys } \\
\text { and rapid damage } \\
\text { assessments }\end{array}$} & $\begin{array}{l}\text { IIIA Post-disaster } \\
\text { surveys }\end{array}$ & $\begin{array}{l}\text { Established - ability to safely } \\
\text { assess extent of regional damage } \\
\text { now possible assuming favourable } \\
\text { weather conditions and ability to } \\
\text { launch UAV systems sufficiently } \\
\text { close to disaster hit areas }\end{array}$ \\
\hline & & $\begin{array}{l}\text { IIIB Post-disaster } \\
\text { rapid damage } \\
\text { assessment }\end{array}$ & $\begin{array}{l}\text { Emerging - detecting damage will } \\
\text { generally be from images captured } \\
\text { by the UAV system. The ability for } \\
\text { the UAV to access sufficient parts } \\
\text { of the damaged asset and sample a } \\
\text { sufficient quantity of damaged } \\
\text { assets is crucial as to the success of } \\
\text { such mission. These efforts could } \\
\text { be hampered (as for Category 3A) } \\
\text { by weather and endurance. }\end{array}$ \\
\hline
\end{tabular}

